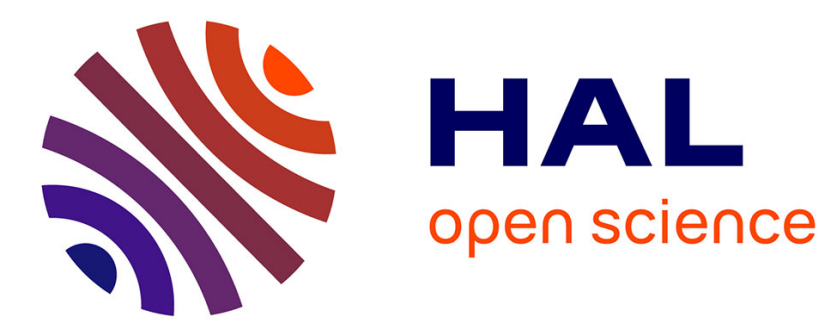

\title{
Interactive Feedback between the Tropical Pacific Decadal Oscillation and ENSO in a Coupled General Circulation Model
}

\author{
Jung Choi, Soon-Il An, Boris Dewitte, W. W. Hsieh
}

\section{- To cite this version:}

Jung Choi, Soon-Il An, Boris Dewitte, W. W. Hsieh. Interactive Feedback between the Tropical Pacific Decadal Oscillation and ENSO in a Coupled General Circulation Model. Journal of Climate, 2009, 22 (24), pp.6597-6611. 10.1175/2009jcli2782.1 . hal-00766389

\section{HAL Id: hal-00766389 \\ https://hal.science/hal-00766389}

Submitted on 10 Jun 2014

HAL is a multi-disciplinary open access archive for the deposit and dissemination of scientific research documents, whether they are published or not. The documents may come from teaching and research institutions in France or abroad, or from public or private research centers.
L'archive ouverte pluridisciplinaire HAL, est destinée au dépôt et à la diffusion de documents scientifiques de niveau recherche, publiés ou non, émanant des établissements d'enseignement et de recherche français ou étrangers, des laboratoires publics ou privés. 


\title{
Interactive Feedback between the Tropical Pacific Decadal Oscillation and ENSO in a Coupled General Circulation Model
}

\author{
JUNG CHOI AND SOON-IL AN \\ Department of Atmospheric Sciences, Global Environmental Laboratory, Yonsei University, Seoul, South Korea \\ BORIS DEWITTE \\ Laboratoire d'Etude en Géophysique et Océanographie Spatiale, Toulouse, France \\ WILLIAM W. HSIEH \\ Department of Earth and Ocean Sciences, University of British Columbia, Vancouver, British Columbia, Canada
}

(Manuscript received 8 August 2008, in final form 7 July 2009)

\begin{abstract}
The output from a coupled general circulation model (CGCM) is used to develop evidence showing that the tropical Pacific decadal oscillation can be driven by an interaction between the El Niño-Southern Oscillation (ENSO) and the slowly varying mean background climate state. The analysis verifies that the decadal changes in the mean states are attributed largely to decadal changes in ENSO statistics through nonlinear rectification. This is seen because the time evolutions of the first principal component analysis (PCA) mode of the decadalvarying tropical Pacific SST and the thermocline depth anomalies are significantly correlated to the decadal variations of the ENSO amplitude (also skewness). Its spatial pattern resembles the residuals of the SST and thermocline depth anomalies after there is uneven compensation from El Niño and La Niña events. In addition, the stability analysis of a linearized intermediate ocean-atmosphere coupled system, for which the background mean states are specified, provides qualitatively consistent results compared to the CGCM in terms of the relationship between changes in the background mean states and the characteristics of ENSO. It is also shown from the stability analysis as well as the time integration of a nonlinear version of the intermediate coupled model that the mean SST for the high-variability ENSO decades acts to intensify the ENSO variability, while the mean thermocline depth for the same decades acts to suppress the ENSO activity. Thus, there may be an interactive feedback consisting of a positive feedback between the ENSO activity and the mean state of the SST and a negative feedback between the ENSO activity and the mean state of the thermocline depth. This feedback may lead to the tropical decadal oscillation, without the need to invoke any external mechanisms.
\end{abstract}

\section{Introduction}

The Pacific decadal oscillation (PDO) pattern is usually defined by the leading principal component analysis (PCA) mode of the sea surface temperature (SST) anomalies in the Pacific Ocean north of $20^{\circ} \mathrm{N}$. Although the PDO was initially defined over the North Pacific, the global SST pattern associated with the PDO index shows an El Niño-Southern Oscillation (ENSO)-like pattern

Corresponding author address: Prof. Soon-Il An, Department of Atmospheric Sciences, Yonsei University, 134 Shinchon-dong, Seodaemun-gu, Seoul 120-749, South Korea.

E-mail: sian@yonsei.ac.kr over the tropical Pacific (Zhang et al. 1997). Hence, it is likely that there is a dynamical linkage between the extratropical PDO and the tropical PDO. Regardless of its main driver [i.e., an unstable air-sea interaction mode proposed by Latif and Barnett (1994) or a stochastically excited resonance mode proposed by Saravanan and McWilliams (1997) and a combined process of that externally forced by ENSO known as "reemergence" and that driven by atmospheric white noise proposed by Alexander et al. (1999) and Newman et al. (2003)], the extratropical PDO signals were considered to be transported into the tropics (e.g., Gu and Philander 1997; Vimont et al. 2003; Kleeman et al. 1999; Nonaka et al. 2002). On the other hand, tropical Pacific variability due 
to ENSO also communicates into the extratropics and generates the extratropical PDO through teleconnection (Cane and Evans 2000; Newman et al. 2003; An et al. 2007; Holland et al. 2007). Thus, a debate is underway regarding whether the extratropical PDO drives the tropical PDO (TPDO), or vice versa.

Recently, it has been suggested that the TPDO could be generated through an internal process of the tropical Pacific without invoking any extratropical influences (Timmermann and Jin 2002; Rodgers et al. 2004; Dewitte et al. 2007b). In other words, TPDO is either stochastically excited (Kirtman and Schopf 1998; Yeh and Kirtman 2004; Burgman et al. 2008; Yeh and Kirtman 2009) or it results from deterministic dynamical processes that are possibly driven by a simple atmosphere-ocean coupling (Timmermann et al. 2003). Although these two mechanisms have different theoretical bases, they share a common feature. That is, the TPDO is characterized by the ENSO-like patterns of anomalous sea surface temperatures (SSTA) and subsurface temperatures, with a time scale of 10-20 yr. Thus, a close relationship between TPDO and ENSO is expected intuitively.

As mentioned above, the TPDO can be generated by intrinsic nonlinear processes. Timmermann and Jin (2002) and Timmermann et al. (2003) emphasized that nonlinearities in the tropical Pacific heat budget could generate El Niño bursting with 10-20-yr time scales, without any external influence or stochastic forcing. The decadal occurrences of strong El Niño events (i.e., El Niño bursting) indicate a stronger El Niño and a weaker La Niña over a long period. This El Niño-La Niña asymmetry enables the ENSO cycle to exert a nonzero forcing on the tropical mean background states, possibly modifying them. For example, Rodgers et al. (2004) used a coupled general circulation model (CGCM) output to show that the SST anomaly pattern of TPDO resembles the residual SST anomaly pattern of El Niño and La Niña, which indicates that the TPDO resulted from the El Niño-La Niña asymmetry. Their point was further supported by Sun and Yu (2009), based on an analysis of observational data. Accordingly, the TPDO is likely to be tightly linked to the intrinsic characteristics of ENSO.

Conversely, the phase change of the TPDO (the change of the mean background climate states) can modify ENSO characteristics such as the amplitude, the period, and the propagation pattern (Wang and Ropelewski 1995; Ye and Hsieh 2006). This phenomenon is referred to as the decadal modulation of ENSO properties. For example, the remarkable climate shift that occurred in the late 1970s had a significant impact on ENSO amplitude and frequency (An and Wang 2000). Also, Fedorov and Philander (2000) stressed the importance of the mean thermocline depth in modifying ENSO characteristics. This mean state's influence on ENSO was confirmed by An and Jin (2000) and Wang and An (2001). Using an intermediate-type coupled model, they showed that observed changes in the mean background state would alter the characteristics of ENSO. Timmermann et al. (1999) concluded that the strengthening of the equatorial thermocline gradient due to global warming very strongly influences the ENSO statistics. On the whole, the TPDO is likely to be an intrinsic mode in the tropical Pacific, and it both affects ENSO and is influenced by ENSO concurrently.

Many physical processes have been proposed to describe the nature of the relationship between the TPDO and ENSO. Jin (2001) and Knutson and Manabe (1998) suggested that the TPDO has essentially the same physical nature as the interannual modes in the tropical ocean dynamics. Also, Kirtman and Schopf (1998) noted that the various mechanisms of ENSO operate depending on the characteristics of the mean state; for example, the delayed oscillator mechanism drives SST anomalies during decades when ENSO variability is high, and atmospheric noise drives SST anomalies when ENSO variability is low. Obviously, the TPDO and ENSO can be dynamically linked under a coupled nonlinear dynamical framework, but they do not interact in a simple linear cause-and-effect relationship (Timmermann 2003). Nevertheless, the previous studies omitted some aspects of the physical mechanisms associated with the cyclic nature of the TPDO. They tended to focus on a unidirectional mechanism in which either the TPDO affects ENSO or the reverse.

Our primary interest in this paper is to address this issue in a fully coupled context that accounts for the interactive feedback mechanism between the TPDO and ENSO using the outputs of a CGCM that exhibits realistic characteristics in terms of decadal variability and ENSO modulation. In light of the results of sensitivity experiments with an intermediate coupled model in which the mean state is prescribed from the CGCM outputs, we propose a mechanism through an asymmetric nature of the ENSO cycle (An et al. 2005a,b; Dewitte et al. 2007b; An 2009) and a modification of the linear stability of ENSO by change in the mean state (An and Jin 2000; An and Wang 2000; Fedorov and Philander 2000).

This paper is organized as follows. The CGCM dataset is outlined in section 2. In section 3, the correlation between the decadal modulations of the ENSO amplitude and the slowly varying mean state is analyzed. The asymmetric structures of ENSO within the different mean states are described in section 4. Also within this section, the modification of the ENSO amplitude by the 
mean states is investigated using an intermediate oceanatmosphere coupled model. Section 5 is devoted to a discussion and concluding remarks.

\section{Data and model}

The oceanic component of the coupled model is taken from the global configuration ORCA2 of the Océan Parallélisé (OPA) 8.2 ocean general circulation model (OGCM) (Madec et al. 1998). The horizontal resolution is $2^{\circ}$ in longitude, and it varies meridionally from $0.5^{\circ}$ around the equator to $2^{\circ}$ in the higher latitude. The meridional grid resolution is increased near the equator to improve the modeling of the equatorial dynamics. The model includes a full thermodynamic sea ice component: the Hibler-type dynamic-thermodynamic Louvain-LaNeuve sea ice model that was developed at the Université Catholique de Louvain (UCL) by Fichefet and Morales Maqueda (1997). The atmospheric component comes from the third version of the Action de Recherche Petite Echelle Grande Echelle (ARPEGE)-climate atmospheric general circulation model developed at MétéoFrance (Déqué et al. 1994). The climate version in its standard configuration uses a T63 triangular horizontal truncation. The vertical direction is discretized into 31 levels (20 levels in the troposphere) using a progressive vertical hybrid coordinate that extends from the ground to a height of about $34 \mathrm{~km}(7.35 \mathrm{hPa})$. The model time step is $30 \mathrm{~min}$ for this resolution and time discretization scheme. Detailed descriptions of the model are provided by Cibot et al. (2005).

The ARPEGE and ORCA/Louvain Ice Model (ORCALIM) models are coupled using the OceanAtmosphere-Sea Ice-Soil (OASIS) 2.5 coupler developed at the Centre Européen de Recherche et de Formation Avancée en Calcul Scientifique (CERFACS) (Valcke et al. 2000). All concentrations of greenhouse gases are fixed at preindustrial levels, and no flux corrections are applied. The atmospheric initial state is set to January conditions that are taken from an uncoupled integration of ARPEGE. The initial ocean temperature and salinity fields are taken from Levitus et al. (1998), and the velocity field is set to zero. We integrated the coupled model over $260 \mathrm{yr}$. We only considered the latest $200-\mathrm{yr}$ period in our subsequent analyses. The model variability has been analyzed in previous studies (Cibot et al. 2005; Dewitte et al. 2007a,b), with a focus on some of the aspects of the seasonal-to-decadal variability. The reader is invited to refer to these studies for an assessment of the realism of the simulation regarding the ENSO mode and decadal variability. Despite a tendency for overly energetic westward mean currents that enhance a nearannual mode and a quasi-biennial ENSO (Dewitte et al. 2007a), the model variability is realistic, particularly since its decadal mode shares many characteristics with observations (Cibot et al. 2005). Dewitte et al. (2007b) focused on the analysis of the vertical structure variability at decadal time scales. As mentioned above in the introduction, the present study complements these previous works by providing a dynamical description and an interpretation of the rectification processes that lead to the low-frequency ENSO modulation.

\section{Correlation between ENSO amplitude and mean climate state}

To determine the frequency and locality of the ENSO variation, we applied a wavelet analysis to an ENSO index, that is, the time series of the Niño-3 SST anomaly (i.e., SST anomaly averaged over the region $5^{\circ} \mathrm{S}-5^{\circ} \mathrm{N}$, $150^{\circ}-90^{\circ} \mathrm{W}$; anomalies are relative to the monthly climatology). The real part of the wavelet transform of the ENSO index is shown in Fig. 1. In this figure, which covers the entire period, the large loadings occur around the 2-yr period, which means that the ENSO period is dominated by a biennial cycle (e.g., Cibot et al. 2005). The biennial tendency of ENSO is a common feature seen in many CGCM results (Guilyardi 2006). Using the wavelet spectrum, we characterize the low-frequency modulation of the ENSO amplitude by computing the interannual (2-7 yr) wavelet variance of a Niño-3 SST anomaly (hereafter referred to as the N3Var index), as described in Torrence and Webster (1998). The N3Var index strongly fluctuates on a decadal time scale with about a 16-yr period, yet it has irregular variability. Consistent with Cibot et al. (2005), large fluctuations of N3Var obviously indicate large amplitudes of ENSO.

The goal of this work is to explore the underlying mechanisms leading to the relationship between the N3Var index and the decadal change in the mean state. The "mean state" in this study does not refer to a stationary state but instead refers to the tropical state over decades or over longer time scales than the interannual time scale. To identify the decadal changes, a 7-yr low-pass filter was applied to the $17^{\circ} \mathrm{C}$ isotherm depth (a proxy for the thermocline depth) and the SST anomalies (hereafter LD17 and LSST, respectively). Note that we take the $17^{\circ} \mathrm{C}$ isotherm depth rather than the $20^{\circ} \mathrm{C}$ isotherm depth as a proxy for the thermocline depth to avoid a possible outcropping of the $20^{\circ} \mathrm{C}$ isotherm that may occur because of the cold bias of this CGCM. However, the decadal mode extracted from the $17^{\circ} \mathrm{C}$ isotherm depth shares a great similarity with that from $20^{\circ} \mathrm{C}$ isotherm depth (see Fig. 6a of Cibot et al. 2005). Also, the 10-yr low-pass filter has been 


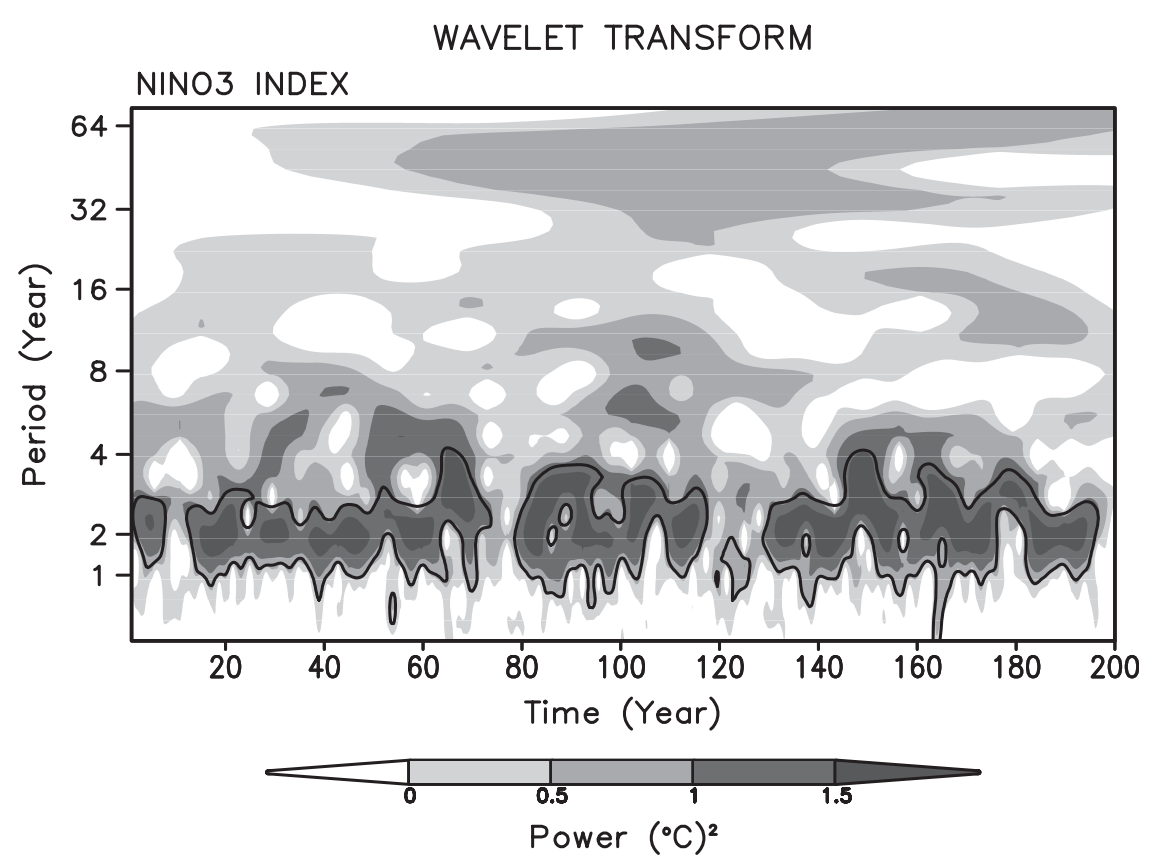

FIG. 1. The real part of the wavelet analysis of the Niño-3 SST anomaly. The contour lines represent the $5 \%$ significance level. The power is calibrated in logarithmic scale.

applied to the data and we got a similar result to that obtained from the 7-yr low-pass-filtered data because of a strong biennial tendency of ENSO in this model (cf. Cibot 2004).

An empirical orthogonal function (EOF) analysis (i.e., principal component analysis) is performed on each lowpass-filtered dataset. The first EOF mode of LSST, which accounts for $38.0 \%$ of the total variance, is dominated by a zonal seesaw structure with a large amplitude pattern in the tropical eastern Pacific, resembling the El Niño mode and a weak opposite amplitude in the western Pacific (Fig. 2a). This is consistent with Dewitte et al. (2007b) and the observed feature (i.e., An et al. 2005b). When the associated principal component (PC) time series is positive, the LSST pattern corresponds to the reduction of the zonal contrast of SST, and vice versa. The first EOF mode (EOF1) of LD17 accounts for $27.3 \%$ of the total variance. Its PC time series has two spectral peaks at 10 and 16 yr. As with LSST, the EOF1 of LD17 exhibits a zonal contrast structure between the central and eastern tropical Pacific Oceans. Dynamically, the deep (shallow) thermocline is associated with the warm (cold) surface temperature, and thus the EOF1 of LD17 is associated with the EOF1 of LSST. Correspondingly, the correlation coefficient between PC1 of LD17 and PC1 of LSST is 0.94. The correlation coefficients between the N3Var index and the time series of each PC reach 0.51 and 0.54 for LSST and LD17, respectively. Both are statistically signifi- cant at the 99\% level (Fig. 3). The correlation coefficients between the 10-yr running variance-weighted skewness (i.e., the third statistical moment divided by standard deviation; An et al. 2005a) of the Niño-3 index and the time series of each PC are 0.29 and 0.26 for LSST and LD17, respectively, and they are statistically significant at the $95 \%$ level. The positive correlation means that the reduction of zonal contrast in the mean SST and in the thermocline slope is associated with stronger ENSO asymmetry (also true with the ENSO variability).

This relationship seems to be counterintuitive because a reduced basin-scale zonal SST gradient results in a reduced Walker circulation (Timmermann 2003) and, finally, a weak atmosphere-ocean coupling. Dewitte et al. (2007b) argued that this counterintuitive relationship may be explained by the increase in higher-order baroclinic mode equatorial wave contributions and their impact on the nonlinear advection during periods of the strong ENSO activity. The dynamical causalities on this coupling between the changes in ENSO activity and those in the mean states will be further investigated in the following section.

\section{Dynamical interpretations}

In this section, we provide clear evidence to demonstrate that changes in the ENSO statistics modify the changes in the mean state, and vice versa. 
(a) SST (>7yr) / EOF1 (38.02\%)

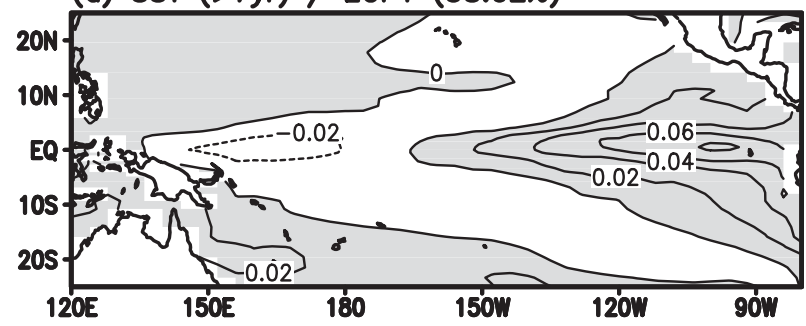

(b) D17 (>7yr) / EOF1 (27.28\%)

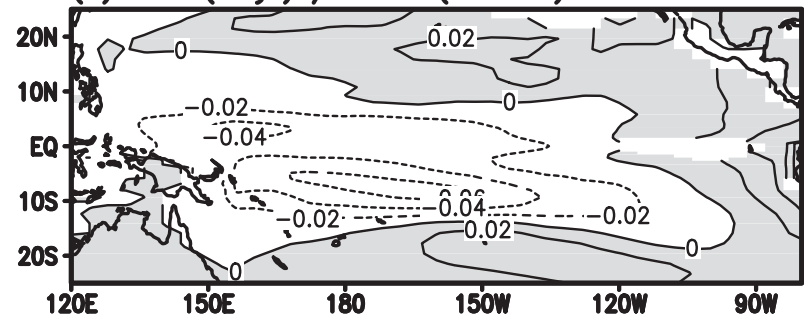

FIG. 2. Spatial pattern of the first EOF mode of (a) the low-pass-filtered SST and (b) the $17^{\circ} \mathrm{C}$ isotherm depth anomalies.

\section{a. Nonlinear rectification of ENSO onto a mean state}

An upscale energy transport, that is, from highfrequency variability to low-frequency variability, is possible through a nonlinear process. For example, the residual from an incomplete compensation between a larger El Niño and a smaller La Niña, associated with the nonlinear process of ENSO (or asymmetric oscillatory behavior of ENSO), can be rectified into the mean state (Jin et al. 2003; Timmermann 2003; Rodgers et al. 2004; Yeh and Kirtman 2004; Schopf and Burgman 2006; Sun and Zhang 2006; An 2009; Sun and Yu 2009; see also the appendix, which elucidates a nonlinear rectification process of ENSO in a simply dynamical system context). In this work, we test whether the rectification is significant in our model. First, we define two regimes based on the leading PC of LD17, each of which indicates different mean state conditions. The first regime is the high-ENSO variability regime, which occurs when the values of the normalized PC of LD17 are greater than 0.5 (hereafter High-Var regime). The second is the low-ENSO variability regime, which occurs when the values for the normalized PC of LD17 are smaller than -0.5 (hereafter Low-Var regime). The choice of a higher threshold, that is, one standard deviation, does not change the composite result (not shown).

Figure 4 shows the evolutions of every El Niño and La Niña event through the Niño-3 SSTA index, and their composite values, for periods during the High-Var regime (Fig. 4a) and periods during the Low-Var regime (Fig. 4b). The "lag 0" refers to each January, when events achieve their maximum phase. In the High-Var

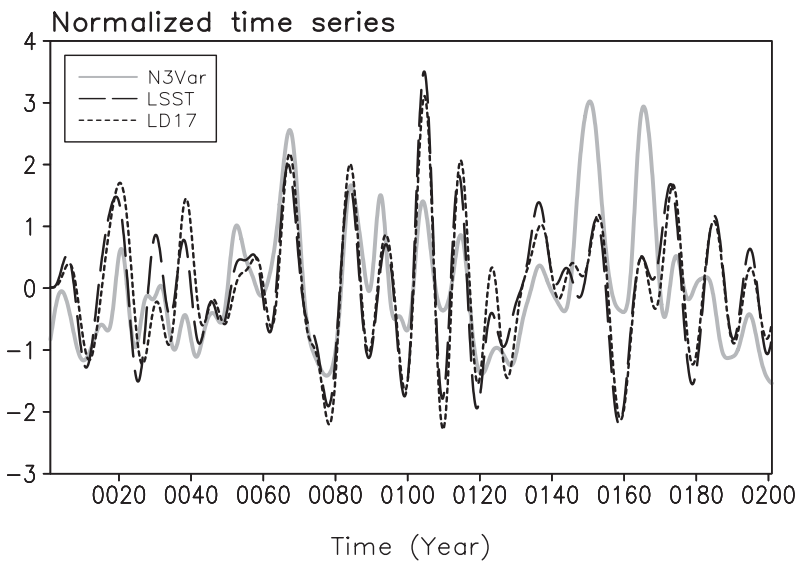

FIG. 3. Gray solid line: time series of the N3Var index. Black short-dashed line: PC time series of first EOF mode for the lowpass-filtered $17^{\circ} \mathrm{C}$ isotherm depth (see Fig. 2b). Black long-dashed line: PC time series of first EOF mode for the low-pass-filtered SST (see Fig. 2a). Time series has been normalized.

regime, the peak amplitudes of the Niño-3 SST anomalies are approximately $\pm 2^{\circ} \mathrm{C}$, whereas the peak amplitudes in the Low-Var regime are approximately $\pm 1^{\circ} \mathrm{C}$. As expected, the amplitude of ENSO in the High-Var regime is larger than the amplitude in the Low-Var regime. The residual heat (i.e., the average of the El Niño and La Niña composites) is positive in the HighVar regime (greater than $0.28^{\circ} \mathrm{C}$ is statistically significant enough to be a nonzero value with $90 \%$ confidence level) but is weakly negative in the Low-Var regime (less than $-0.26^{\circ} \mathrm{C}$ is statistically significant enough to be a nonzero value with $90 \%$ confidence level). Accordingly, El Niño (La Niña) events are stronger than La Niña (El Niño) events in the High-Var regime (Low-Var regime). Previous observational studies suggested this asymmetric characteristic of ENSO (An and Jin 2004; An 2009; Sun and Yu 2009).

The dominant periods of ENSO for both regimes are obtained by computing a global wavelet spectrum of the Niño-3 index corresponding to each regime (Fig. 5). A global wavelet spectrum corresponds to the average of all the wavelet spectrums with respect to each period. To facilitate the comparison, each variance is normalized by the total variance over each mean state. The spectrum of ENSO associated with the Low-Var regime sharply peaks around $1.9 \mathrm{yr}$, while the High-Var regime peaks around $2.3 \mathrm{yr}$. The strongest variability (when the normalized power is strongest than 0.2 ) has a range from 1.8 to $2.3 \mathrm{yr}$ in the Low-Var regime; it is relatively broader for the High-Var regime ranging from 1.8 to $2.7 \mathrm{yr}$. This model agrees with the observed tendency of a direct proportionality between the period and amplitude of ENSO. For example, after the climate shift in the 


\section{(a) NINO3 / High-Var}

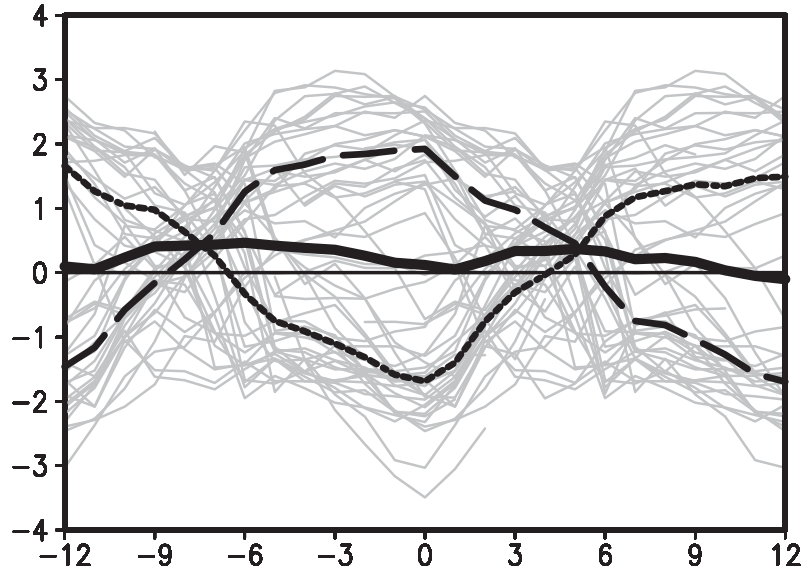

(b) NINO3 / Low-Var

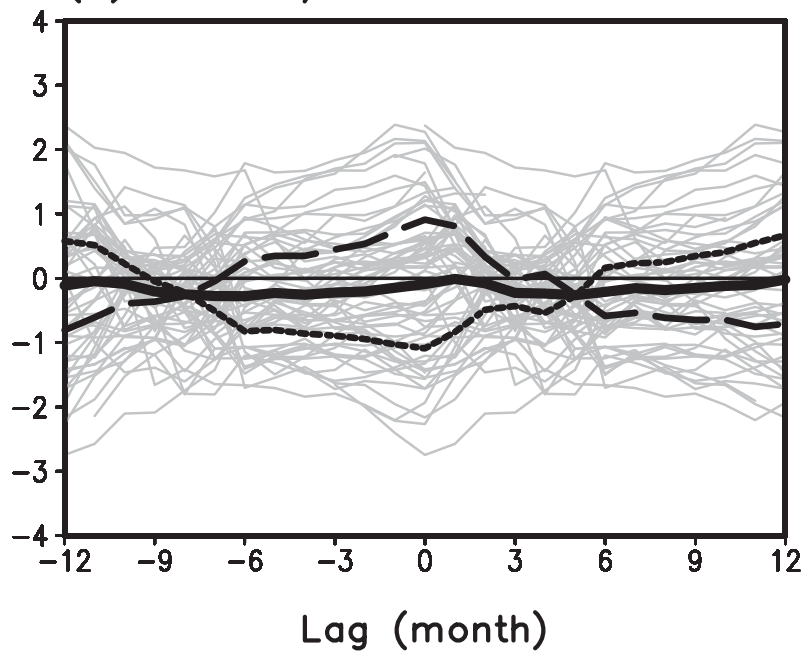

FIG. 4. Diagram of the Niño-3 SSTA $\left({ }^{\circ} \mathrm{C}\right)$ belonging to (a) the High-Var regime and (b) the Low-Var regime. The development to the decay of ENSO are shown. The thick long-dashed and dotted lines indicate the composite of El Niño events and La Niña events, respectively. The average of all lines is represented by the thick solid line.

late 1970s, the amplitude of ENSO became larger and its period became longer compared with the previous decades (An and Wang 2000).

The asymmetric feature of ENSO is also found in the ocean subsurface, where changes associated with ENSO can be represented by the 7-yr high-pass-filtered $17^{\circ} \mathrm{C}$ isotherm depth anomalies (hereafter HD17). The HD17 accounts for the thermocline depth anomaly in the tropical ocean. To further explore the asymmetric features of ENSO, a first step is to perform an EOF analysis on the HD17. The first and second leading EOF modes (EOF1 and EOF2, respectively) of the HD17 account for 37.5\% and $26.1 \%$ of the total variance, respectively. The EOF1 of the HD17 exhibits a zonal contrast pattern, with

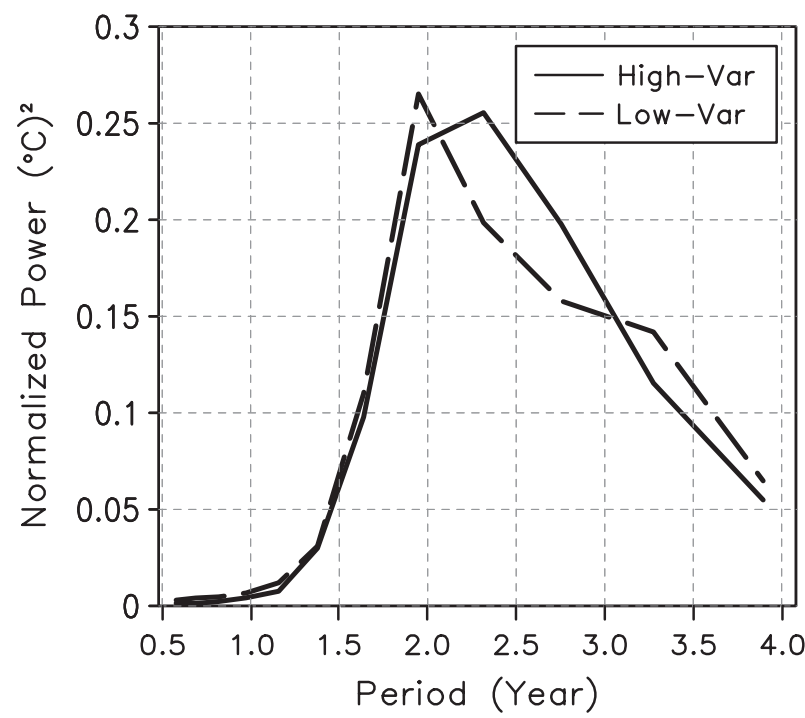

FIG. 5. Global wavelet spectrum of the Niño-3 index corresponding to the High-Var and Low-Var regimes.

a pole near the date line and another in the eastern coastal region (Fig. 6a). The EOF2 of the HD17 exhibits a zonal-symmetric pattern with a northern strip along $9^{\circ} \mathrm{N}$ and a southern strip along the equator (Fig. 6b). The $\mathrm{PC} 1$ varies in phase with ENSO (e.g., the Niño-3 index), and for the most part $\mathrm{PC} 2$ leads $\mathrm{PC} 1$ by a $90^{\circ}$ phase. Thus, EOF1 and EOF2 can be considered as patterns at the mature phase and at the transition phase of ENSO, respectively. Very similar leading modes of the thermocline depth as the $20^{\circ} \mathrm{C}$ isotherm depth were also found in observations (An et al. 2005b).

As a second step in this investigation, identifying the phase relationship between PC1 and PC2 of the HD17, the scatter diagrams between $\mathrm{PC} 1$ and $\mathrm{PC} 2$ are derived and presented in Figs. $6 c$,d. To classify the ENSO characteristics as a function of an amplitude variability regime, we separately display the scatter features for the High-Var regime and the Low-Var regime. The $x$ axis and $y$ axis represent $\mathrm{PC} 1$ and $\mathrm{PC} 2$, respectively.

The ENSO is generally progressing as a clockwise rotation, with upper- and lowermost points in an imaginary circle (Fig. 6c) that correspond to the transition phase from La Niña to El Niño and that from El Niño to La Niña, respectively. In Fig. 6c, the imaginary circle is easily visualized and appears well defined, which supports the idea that an ENSO for a High-Var regime may be considered as an oscillatory mode. Another interesting feature in Fig. $6 \mathrm{c}$ is that the imaginary circle is not symmetric with respect to the zero point, as we would expect from Fig. 4. Usually, the amplitude of El Niño (right side of curve) is larger than that of La Niña (left side of curve), whereas the amplitude at the transition 
(a) D17 (<7yr) / EOF1 (37.5\%)

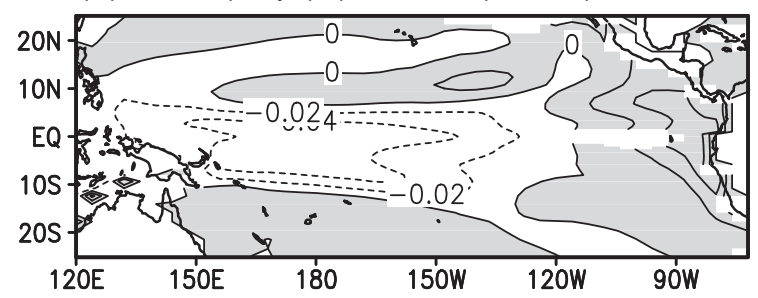

(b) D17 (<7yr) / EOF2 (26.1\%)

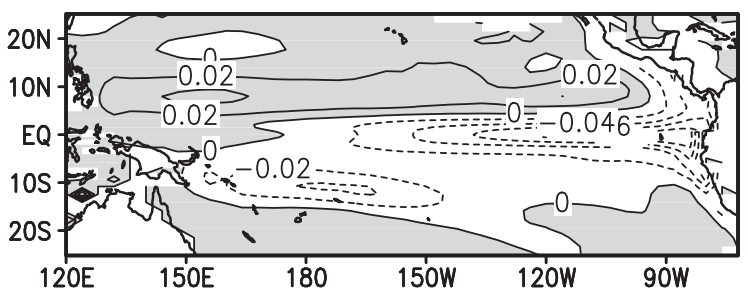

(c) High-Var

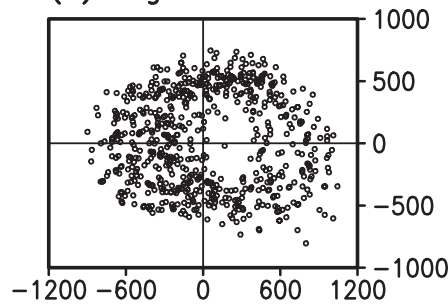

(d) Low-Var

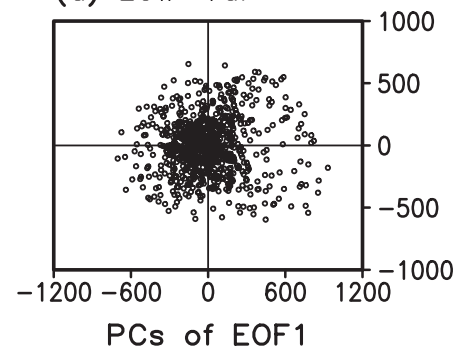

कृ

옥 กั

FIG. 6. (a) Spatial pattern of the first EOF mode and (b) the second EOF mode of high-pass-filtered isotherm depth $\left(17^{\circ} \mathrm{C}\right)$. The corresponding scatterplots for (c) High-Var and (d) Low-Var in PC1-PC2 plane are shown on the right-hand side.

phase (the recharge phase; top of curve; Jin 1997) is similar to the other transition phase (the discharge phase; bottom of curve). In other words, the mature phases are asymmetric, whereas the transition phases appear to be symmetric. Therefore, the residual pattern due to the asymmetry of ENSO is like the spatial pattern of the first EOF mode shown in Fig. 6a (i.e., a canonical ENSO pattern at the mature phase; see An 2009). Conversely, as seen in Fig. 6d, the dots in the Low-Var regime are strongly scattered and are not organized into any particular form. Also, the amplitudes of the PC in the Low-Var regime are generally smaller that those in the High-Var regime. Thus, ENSOs in the High-Var regime behave as a self-sustained oscillatory mode, while those in the Low-Var regime behave very likely as a damped oscillatory mode or may still be a self-sustained mode with smaller amplitude.

The nonlinear principal component analysis (NLPCA) (Hsieh 2001, 2004, 2007) of HD17 is used to confirm and complement the above interpretation. It first reveals a canonical oscillatory trajectory in the PC time series space in the High-Var regime, as mentioned above. As in An et al. (2005b), the NLPCA was applied to the leading 5 PCs of the EOFs, separately for the High-Var and the Low-Var regimes. For the High-Var case (Fig. 7a), the NLPCA mode explains $84.7 \%$ of the variance of the 5 inputs (PC1 to PC5), while the linear PCA mode (dashed line) explains only $53.9 \%$ of the variance. For the Low-Var case (Fig. 7b), the NLPCA mode explains $47.8 \%$ of the variance of the 5 inputs (PC1 to PC5) versus $45.3 \%$ for the linear PCA mode (dashed line).
The NLPCA generalizes the straight line solution of the PCA as either an open curve or a closed curve. The selection of either an open or closed curve and the smoothness of the curve fits to the data were objectively determined by an information criterion (Hsieh 2007). Figure 7 shows a well-defined cyclic trajectory in the High-Var regime, although the cyclic trajectory is not identified in the Low-Var regime (in the figure, these trajectories are only shown in the 2D space PC1-PC2, since the higher modes have less variance, i.e., $3.8 \%$, $2.8 \%, 1.7 \%$ sequentially). It is also possible to use a closed curve to fit the data for the Low-Var regime, explaining more variance than the open curve; however, such a solution will have many neighboring points assigned with very different nonlinear PC values-this inconsistency is penalized in the information criterion (Hsieh 2007), hence the closed curve solution is rejected. So the NLPCA has objectively determined that the oscillation has a well-defined cycle of 4 distinct phases in the High-Var case but not in the Low-Var case. Thus, our more objective approach demonstrates that ENSOs in the High-Var regime act like an oscillatory mode, while those in the Low-Var regime act like a damped mode. Note that An (2009) dragged out the residual effect of ENSO using the NLPCA mode of the observed tropical Pacific thermocline depth anomalies and showed that the residual thermocline resembles the actual interdecadal change in the mean state of the thermocline (see Fig. 9 of An 2009).

To see whether the residual pattern due to the asymmetric ENSO cycle resembles the TPDO pattern, we 
(a) High-Var

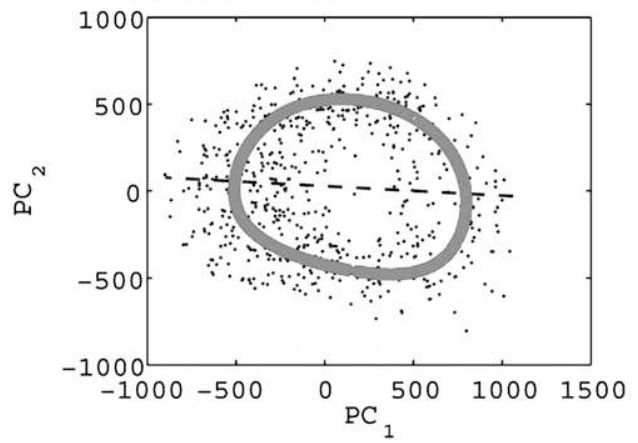

(b) Low-Var

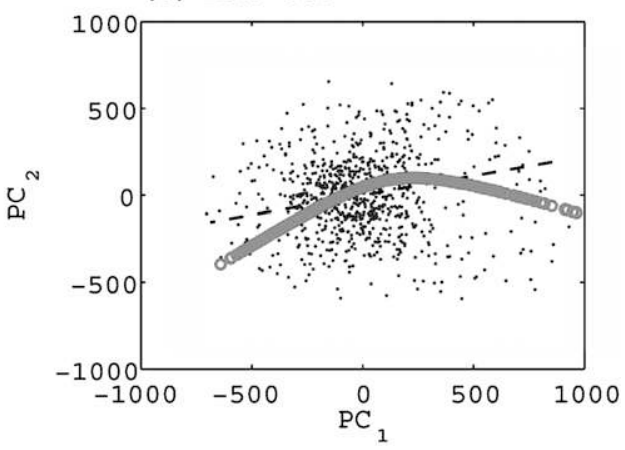

FIG. 7. The projected NLPCA mode 1 of the thermocline depth anomaly onto the PC1-PC2 space for the (a) High-Var and (b) Low-Var regimes is indicated by (overlapping) circles, the PCA by thin dashed lines, and the projected data points by the scattered dots. The NLPCA mode 1 approximation to the data traced out a closed curve (a) and an open curve (b). The progression of the system with time is primarily clockwise along the closed curve. The NLPCA mode 1 explains $84.7 \%$ (for the High-Var case) and $47.8 \%$ (for the Low-Var case) of the variance of the 5 inputs (PC1 to PC5).

calculate the residuals by simply taking the 7 -yr running average of the high-pass-filtered SST and thermocline depth anomalies and apply EOF analysis to the residuals. As shown in Fig. 8, the first EOF modes of the residuals are very similar to the first EOF modes of TPDO (see Fig. 2). The pattern correlation between the first EOFs of SST is 0.84 and that for thermocline depth 0.89 . Thus, there exists an interactive feedback process between the ENSO and TPDO.

\section{b. Influences of mean state on ENSO}

To investigate the role of the mean climate state in changing the ENSO amplitude, we perform an eigenanalysis, in the Pacific domain only, using a linearized intermediate coupled model that is similar to the CaneZebiak model (Zebiak and Cane 1987). Our model differs from the original Cane-Zebiak model in that it employs the smoothed versions of the subsurface temperature parameterization, the vertical advection, the convergence feedback, and other parts (more details are provided in An et al. 2004 and Bejarano 2006). These modifications obviously contribute to the regular ENSO oscillations having a small skewness, but overall the period and amplitude (or growth rate) of the ENSOs in both models are similar.

In this work, we control the background states in the model. First, four sets of mean background states (the SST and $17^{\circ} \mathrm{C}$ isotherm depth) are computed by averaging over the maximum phases of both the High-Var regime and the Low-Var regime and over two intermittent phases between the High-Var and Low-Var regimes according to the phase of LD17 (see Table 1). Using these four sets of mean background states, we separately compute the Jacobian matrix (i.e., the linear dynamics operator of the intermediate coupled model) using a perturbation method. In this method, the matrix elements are computed from small variable perturbations and their simulated corresponding time derivatives. Then, the eigenmodes are computed using standard numerical eigenanalysis techniques.

To explore the background effect on ENSO stability, the mean SST and the thermocline depth (i.e., the $17^{\circ} \mathrm{C}$ isotherm depth, D17) for four phases (two peak phases and two transition phases after the PC of the first EOF of LD17) are incorporated into the intermediate coupled model. In this model, the mean SST is used to determine the atmospheric heating and the total temperature field for the ocean surface. The total temperature field in turn modifies the anomalous zonal and meridional advections of the mean temperature gradients. The mean thermocline depth is used as a parameter in a calculation of the subsurface temperature, which is later used for calculating the vertical temperature gradient (Zebiak and Cane 1987). Hereafter, we denote the four phases as $H$, $\mathrm{H} 2 \mathrm{~L}, \mathrm{~L}$, and $\mathrm{L} 2 \mathrm{H}$. The " $\mathrm{H}$ " and " $\mathrm{L}$ " indicate the peak phases of 1-yr duration corresponding to the positive (High-Var regime) and negative (Low-Var regime) PC of LD17, respectively. The "H2L" represents the transition phase of 1-yr duration from $\mathrm{H}$ to $\mathrm{L}$, and vice versa, for "L2H" (Table 1). If other compositions of the mean state are used, we get qualitatively the same results. To reveal the strongest response of the mean state change, we used 1-yr duration averaging at each phase. The 1-yr average is actually a composite of several decadal events; thus, it does not indicate a state for a particular year.

Figure 9 shows the growth rate and frequency of the leading eigenmodes associated with the background mean states for the four phases. The squared mark with 
(a) SST (<7yr) / 7yr-rmean/ EOF1 (49.12\%)

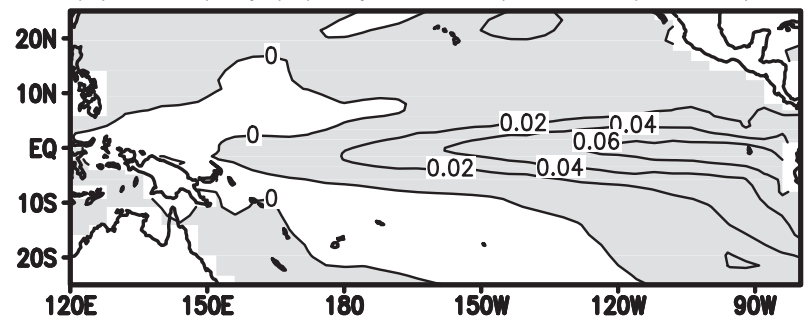

(b) D17 (<7yr) / 7yr-rmean/ EOF1 (41.04\%)

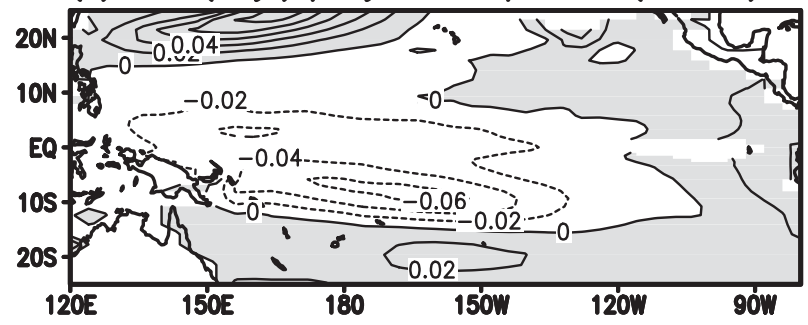

FIG. 8. Spatial pattern of the first EOF mode of (a) the 7-yr running-averaged high-pass-filtered SST and (b) the 7-yr runningaveraged high-pass-filtered $17^{\circ} \mathrm{C}$ isotherm depth anomalies.

cross indicates the control (CNTL) experiment, which is simulated with original basic state of Cane-Zebiak model. When both the SST and the thermocline depth background states are used in the model (as indicated by a closed triangle), the growth rate and frequency associated with the High-Var regime (experiment $\mathrm{H}$ ) are 0.051 and $0.285 \mathrm{yr}^{-1}$, respectively, while those associated with the Low-Var regime (experiment L) are 0.030 and $0.313 \mathrm{yr}^{-1}$, respectively. The growth rate of the Low-Var regime is positive, even though the ENSOs for the Low-Var regime resemble a damped oscillatory mode. In addition to the SST and thermocline states, there are other factors in the CGCM that contribute to changing ENSO characteristics, which are not represented in this intermediate coupled model. These include a richer vertical structure of thermocline that can impact ENSO characteristics through a redistribution of the energy onto each baroclinic mode (cf. Dewitte et al. 2007b), nonlinear processes that exists in a CGCM but not in a linear model (cf. Timmermann et al. 2003), and stochastic processes (Penland and Sardeshmukh 1995; Chang et al. 1996; Thompson and Battisti 2000; and others). Because of this mismatch, the results are not quantitatively comparable. Nevertheless, the results indicate that the eigenanalysis produces qualitatively consistent results with the CGCM output, which implies that part of the changes in the ENSO characteristics are attributable to the changes in the mean SST and the mean thermocline.

We assess the relative contributions of the background SST and the thermocline depth to identify which
TABLE 1. Experiment description for the eigenanalysis.

\begin{tabular}{|c|c|c|}
\hline & \multicolumn{2}{|c|}{ Description } \\
\hline & Normalized LD17 & Mean state \\
\hline $\mathrm{H}$ & $\approx+0.5$ & High-Var regime \\
\hline $\mathrm{H} 2 \mathrm{~L}$ & $\approx 0.0$ & $\begin{array}{l}\text { Transition regime } \\
\quad(\text { High-Var } \rightarrow \text { Low-Var) }\end{array}$ \\
\hline $\mathrm{L}$ & $\approx-0.5$ & Low-Var regime \\
\hline $\mathrm{L} 2 \mathrm{H}$ & $\approx 0.0$ & $\begin{array}{l}\text { Transition regime } \\
\quad \text { (Low-Var } \rightarrow \text { High-Var) }\end{array}$ \\
\hline
\end{tabular}

mean background states have the most influence on the model ENSO. The model uses either the mean SST or the mean thermocline depth, but not both. When only the mean SST is incorporated into the model, the growth rate associated with the condition at the $\mathrm{H}$ phase is larger than that associated with the condition at the $\mathrm{L}$ phase. This is similar to the case when both the SST and the thermocline background states are considered (Fig. 9). The period of ENSO for the $\mathrm{H}$ phase is longer than that for the L phase. Conversely, in the sensitivity experiment to thermocline depth only (as indicated by open circles), the result is opposite (there is a smaller growth rate and a shorter period for the $\mathrm{H}$ phase and a larger growth rate and a longer period for the $\mathrm{L}$ phase). Therefore, these results imply that the warming (cooling) of the ocean surface can cause an increase (decrease) in the ENSO variability, while the deepening (shoaling) of the thermocline can cause suppression (enhancement) of ENSO variability. This result provides a reasonable answer on "a counterintuitive argument," referring that the deepening (shoaling) of mean thermocline depth in the eastern (western-central) $\mathrm{Pa}$ cific is supposed to go along with the weak ENSO variability (e.g., Meehl et al. 2001) but is correlated to the strong ENSO variability in this model as well as others (e.g., Timmermann 2003; Rodgers et al. 2004; An et al. 2005a; Cibot et al. 2005). In other words, the strong ENSO variability is mainly due to the change in the mean SST, while, as expected, mean thermocline plays a role of suppression of ENSO activity.

To investigate what process plays a dominant role in destabilizing ENSO, we further perform the eigenanalysis using the same model used above. In this intermediate model, the prescribed mean SST modifies the atmospheric heating and zonal and meridional SST advections (e.g., $-u^{\prime} \bar{T}_{x}-v^{\prime} \bar{T}_{y}$ ). Here, we confine the modified mean SST effect into one of the terms and perform the experiment only for the High-Var regime case. As summarized in Table 2, the modified atmospheric heating by changes in the mean SST promotes the growth rate most dominantly, indicating that the warming of the background SST causes destabilizing of 


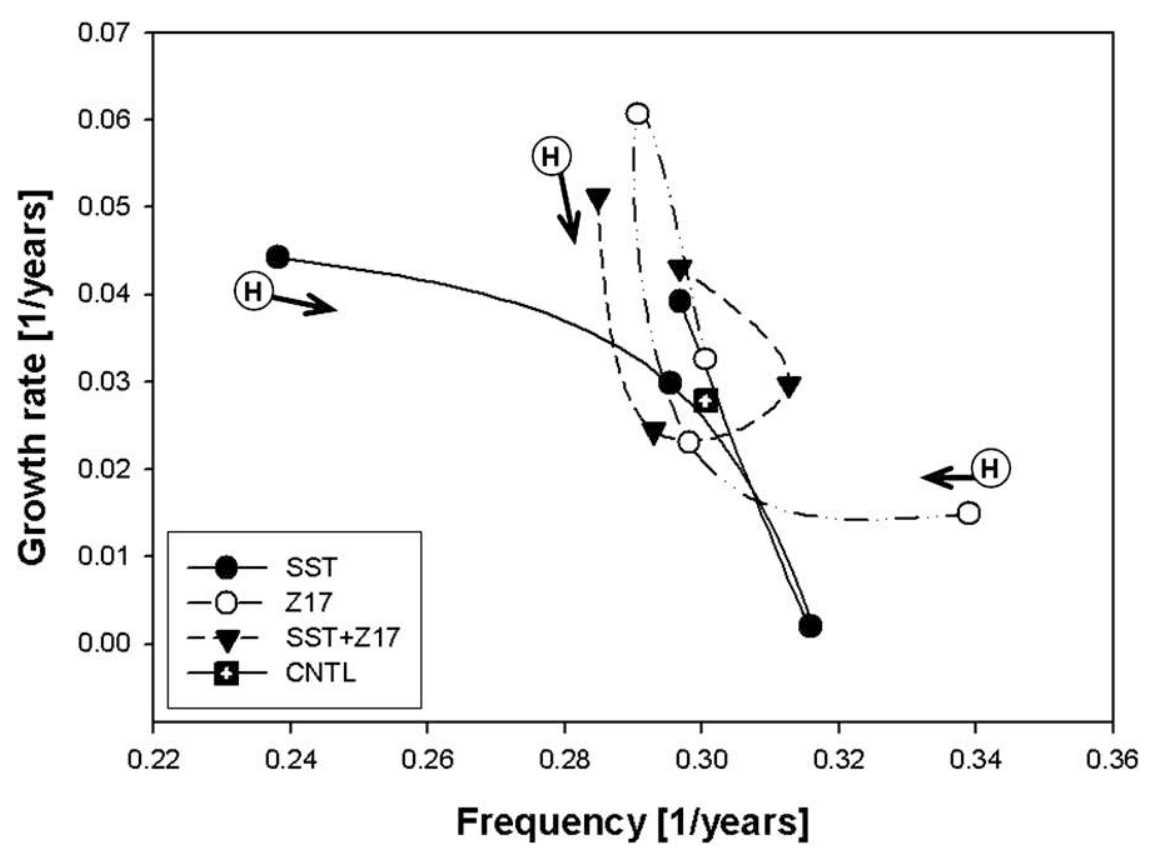

FIG. 9. Growth rate and frequency plot obtained from the linearized intermediate ENSO model. The closed circles (open circles) represent the leading eigenmode using anomalous SST conditions (anomalous thermocline depth conditions). The closed triangles represent the leading eigenmode using both conditions. The experiments $(\mathrm{H}, \mathrm{H} 2 \mathrm{~L}, \mathrm{~L}$, and $\mathrm{L} 2 \mathrm{H})$ are represented sequentially, following the arrows for each case. CNTL indicates a leading eigensolution without any modification.

ENSO mainly by promoting the atmospheric response to a given SST anomaly. ${ }^{1}$ To check whether this effect is dominant in the CGCM, we measure the atmospheric sensitivity to SST anomaly in a simple yet acceptable way by calculating a linear regression fit of the wind stress anomaly over Niño-4 region with respect to SST anomaly over Niño-3 region from the CGCM data (e.g., Guilyardi 2006). The slope of the regression line for the High- and Low-Var regimes is $5.1 \times 10^{-3} \mathrm{~Pa}$ ${ }^{\circ} \mathrm{C}^{-1}$ and $4.8 \times 10^{-3} \mathrm{~Pa}^{\circ} \mathrm{C}^{-1}$, respectively, meaning that the atmosphere more strongly responds to the SST anomaly during the High-Var regime rather than the Low-Var regime. Furthermore, the effect of the modified mean thermocline depth is also tested to see whether the change in the eastern Pacific thermocline is dominantly influencing ENSO activity or whether the change in the central-western Pacific thermocline is altering ENSO activity over the associated area only. The results support the idea that the suppressing effect by deepening of the mean thermocline during the High-Var

\footnotetext{
${ }^{1}$ In the Cane-Zebiak model, the atmospheric heating due to the anomalous latent heating is parameterized based on the mean SST and SST anomaly as follows: $\dot{Q}=\alpha \times$ SSTA $\times$ $\exp \left[\left(T_{c}-30^{\circ} \mathrm{C}\right) / 17.0\right]$, where $T_{c}$ is the mean SST. Thus, the warmer mean SST promotes the sensitivity of the atmospheric heating to the changes in SSTA.
}

regime and the intensifying effect by shoaling of the mean thermocline during the Low-Var regime are dominated by the eastern Pacific thermocline.

As a complementary and final experiment in this paper, we perform a time integration of the original CaneZebiak model into which the background mean SST and thermocline are incorporated as we did above in the eigenanalysis of a linearized version of Cane-Zebiak model. The original Cane-Zebiak model is a fully nonlinear version and its background states are seasonally varying. Thus, apart from the eigenanalysis of a linearized version of Cane-Zebiak model, we can include the stochastic processes in the time integration of the original Cane-Zebiak model. This experiment is worthwhile because many studies argued that the stochastic processes could generate the major characteristics of ENSO

TABLE 2. Growth rate and frequency of ENSO mode obtained from the eigenanalysis of an intermediate model. The modification of the mean SST is incorporated into only one term of the model. See text for details. Units are $0.1 \mathrm{yr}^{-1}$ for frequency.

\begin{tabular}{ccccc}
\hline $\begin{array}{c}\text { Term in which mean } \\
\begin{array}{c}\text { SST is prescribed } \\
\text { from the CGCM }\end{array}\end{array}$ & $\begin{array}{c}\text { Atmospheric } \\
\text { heating }\end{array}$ & $\begin{array}{c}\text { Zonal } \\
\text { advection }\end{array}$ & $\begin{array}{c}\text { Meridional } \\
\text { advection }\end{array}$ & All \\
\hline Growth rate & 0.405 & 0.294 & 0.373 & 0.443 \\
Frequency & 3.033 & 2.880 & 2.651 & 2.381 \\
\hline
\end{tabular}


as much as the chaotic dynamics could (e.g., Penland and Sardeshmukh 1995; Chang et al. 1996; Thompson and Battisti 2000; Burgman et al. 2008; Yeh and Kirtman 2009). Therefore we can test the ENSO modulation by changes in the background state under a stable regime of ENSO. Before starting to run the model, we reduce the coupling parameter down to the stable regime so that the model cannot produce a self-sustained oscillation on its own. To generate ENSO, a random noise is added whose spatial pattern is a bell shape centered at the equatorial western Pacific. The random noise amplitude is given as 0.035 dyne $\mathrm{cm}^{-2}$, which is known to be the amplitude of the surface zonal wind stress associated with the Madden-Julian oscillation in the tropical Pacific (Kessler and Kleeman 2000). Time integration for each experiment is performed for $500 \mathrm{yr}$. The ENSO activity of each experiment is measured by calculating the standard deviation of Niño-3 index. When changes in the mean SST and the thermocline depth associated with High-Var regime are adopted separately into the model, the standard deviation of the simulated Niño-3 index are $0.82^{\circ}$ and $0.18^{\circ} \mathrm{C}$, respectively, while counterparts associated with the Low-Var regime are $0.038^{\circ} \mathrm{C}$ (mean SST modified) and $1.66^{\circ} \mathrm{C}$ (mean thermocline modified), respectively. Thus, warming in the mean SST and deepening of the mean thermocline during the High-Var regime promote intensification and suppression of ENSO activities, respectively, and opposite cases associated with the Low-Var regime are also true. Moreover, the intensified ENSO is simulated with a relatively longer period (not shown). These time integrations of the original Cane-Zebiak model are consistent with the eigenanalysis. Thus, the ENSO activity subjected to stochastic processes in a stable regime is modified by changes in the mean states in a similar manner as shown in the eigenanalysis.

\section{Discussion and conclusions}

We use the outputs of a coupled general circulation model (CGCM) to investigate the interaction mechanism between a low-frequency modulation of ENSO statistics and the slowly varying mean state in the tropical Pacific. First, we provide evidence that the most dominant decadal changes in both the mean SST and the thermocline depth (i.e., the first EOF modes) are significantly correlated to the decadal modulation of ENSO statistics, including its variance and skewness. We propose that the nonlinear dynamical process initiates this strong correlation. Second, using the intermediate coupled model, we verify that the dominant decadal changes in the mean states (here, the SST and thermocline are used) represented by the first EOF mode can effectively modify the ENSO statistics. Combining these two findings, we conclude that there very likely exists an interactive feedback mechanism between the slowly varying mean state and the ENSO variability in this CGCM. More specifically, there exists a positive feedback with the mean SST and a negative feedback with the mean thermocline depth.

The above findings lead us to the following hypothesis on the tropical Pacific decadal oscillation, which to a certain extent was raised by Sun and Yu (2009), but here we provide more convincing evidence. As depicted on the schematic of Fig. 10, this oscillation is possibly generated through the following sequential processes. First, in the unstable regime, the ENSO amplitude and asymmetry increase. Residual heat in both the ocean surface and subsurface associated with the asymmetric nonlinear ENSO cycle then leads to the warming of the sea surface and to the deepening of the thermocline depth in the tropical eastern Pacific. The warmed mean SST plays a role in amplifying the ENSO variability, while the deepened mean thermocline in the eastern Pacific tends to reduce the ENSO variability. Because of the negative feedback between mean thermocline depth and this ENSO variability, the stability of ENSO shifts toward the stable regime. In the stable regime, the ENSO cycle becomes symmetric, so that there is no further accumulation of heat. As a result, the mean thermocline should shoal back to a normal condition, and the mean surface temperature should return to its normal condition. The shallow thermocline provides a favorable condition for a larger variability in ENSO, so that ENSO returns to the unstable regime. Accordingly, the combined effect of the positive feedback between ENSO activity and the SST climate state, and the negative feedback between ENSO activity and the thermocline climate state, can generate the tropical Pacific decadal oscillation.

However, there are several caveats to our hypothesis. Our eigenanalysis does not account for a circumstance when the negative feedback overwhelms the positive feedback. This turning point between two opposite feedbacks could provide a potential key component for regulating the time scale of the tropical Pacific decadal oscillation. Jin et al. (2001) suggested that oceanic Rossby waves play an important role in the decadal mode in the tropics. However, we did not consider any factors that control the period of the decadal oscillation. Therefore, further validations are needed to understand the regulation of the time scale of the TPDO. Another caveat to our approach is that we have prescribed a mean state while neglecting other forcing mechanisms. In fact, the amplitude of ENSO can be changed by a number of other mechanisms not fully considered 


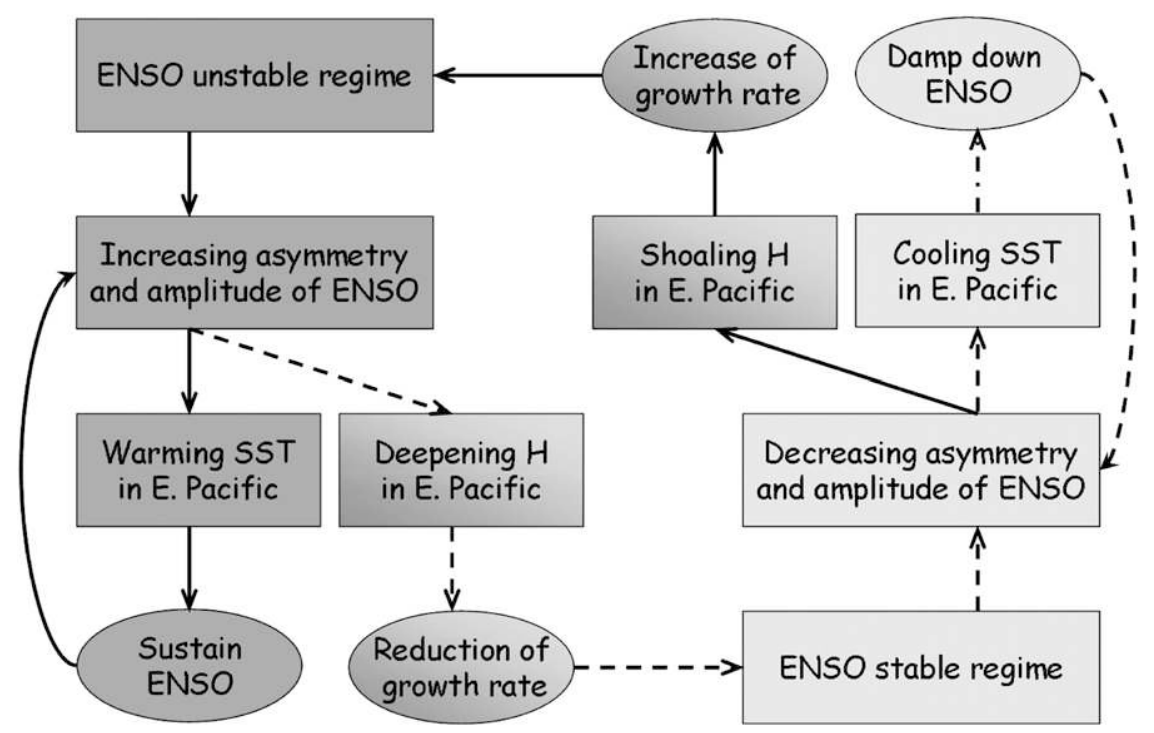

FIG. 10. Schematic diagram showing the turnaround mechanism of decadal variability in the tropical Pacific.

here, such as stochastic forcing or an external influence. It is nevertheless interesting to note that the tropical variability in this model is somewhat isolated from the extratropical oceanic influences, since the propagation of spiciness anomalies are not observed (Cibot et al. 2005). This supports the existence of a tropical mechanism for the decadal variability in the tropical Pacific.

Typically in the tropical Pacific, a deepening of the eastern thermocline or a slope reduction of the equatorial thermocline is expected to accompany the reduced ENSO activity (Zebiak and Cane 1987). However, the majority of CGCMs provide a counterintuitive behavior [e.g., ECHAM4/Ocean Isopycnal Model 3 (OPY3) (Timmermann 2003), ECHAM4/Global Hamburg Ocean Primitive Equation model (HOPE-g) (Rodgers et al. 2004), Meteorological Research Institute 2 (MRI2) and Geophysical Fluid Dynamics Laboratory (GFDL) R30 (An et al. 2005a)], similar to our CGCM. Our hypothesis could provide a key to describe this inconsistency, particularly regarding the competition between the two opposite feedbacks. Also, Dewitte et al. (2007b) proposed a tropical mechanism that explains why a flattening thermocline is associated with a larger ENSO modulation. This mechanism fits with the dynamical interpretation of the model ENSO stability diagnosed in this study. As shown here, the flattening thermocline also leads to a reduced ENSO growth rate, which supports the existence of the proposed mechanism of a decadal mode (Fig. 10).

Acknowledgments. This research was performed under the support of "National Comprehensive Measures against Climate Change" Program by Ministry of Environment, South Korea (Grant 1600-1637-301-210-13) and by the Korea Research Foundation Grant funded by the Korean Government (MOEHRD, Basic Research Promotion Fund, KRF-2007-313-C00784). WWH is supported by the Natural Sciences and Engineering Research Council of Canada. S.-I. An and B. Dewitte also benefited from support of the Centre National de la Recherche Scientifique (CNRS) through a Science and Technology Amicable Research (STAR) program. J. Choi is supported by the Seoul Fellowship.

\section{APPENDIX}

\section{An Interpretation of Nonlinear Rectification of ENSO}

The El Niño amplitude is generally larger than La Niña amplitude so that the residual after long-term average remains. This residual can be rectified into the climate state (An and Jin 2004; Rodgers et al. 2004). Here, we formulate a simple dynamical system to depict the nonlinear rectification effect as mentioned above.

The El Niño-La Niña asymmetry is obviously due to the various nonlinear processes (An 2009). Among these nonlinear processes, the role of the nonlinear dynamical heating in driving the El Niño-La Niña asymmetry was strongly stressed (An and Jin 2004). The nonlinear dynamical heating $(\mathrm{NDH})$, especially the vertical thermal advection that is the largest among others in the observations in the eastern equatorial Pacific (An and Jin 2004), is represented as $-w^{\prime} \partial T_{E}^{\prime} / \partial z$, where the prime 
indicates anomaly. In the following, the rectified effect due to this nonlinear vertical advection term will be depicted by using a box-averaged SST equation over the equatorial eastern Pacific. The SST equation is similar to that in Jin (1997) but was modified to include the nonlinear vertical advection term. The nonlinear SST equation is

$$
\frac{\partial T_{E}}{\partial t}=\cdots-\alpha T_{E}-w \frac{\partial T_{E}}{\partial z}
$$

where the subscript " $E$ " indicates the equatorial eastern Pacific. To make the case simpler, other thermal advection terms are omitted. Equation (A1) is separated into the slowly varying mean (i.e., mean quantities) and deviation (i.e., ENSO quantities) equations by adopting the rule of $\overline{T_{E}^{\prime}}=0$. After some manipulations, we have

$$
\begin{aligned}
\frac{\partial \overline{T_{E}}}{\partial t}= & \cdots-\alpha \overline{T_{E}}-\bar{w} \frac{\partial \overline{T_{E}}}{\partial z}-\overline{w^{\prime} \frac{\partial T_{E}^{\prime}}{\partial z}} ; \\
\frac{\partial T_{E}^{\prime}}{\partial t}= & \cdots-\alpha T_{E}^{\prime}-\bar{w} \frac{\partial T_{E}^{\prime}}{\partial z}-w^{\prime} \frac{\partial T_{E}}{\partial z} \\
& -w^{\prime} \frac{\partial T_{E}^{\prime}}{\partial z}+\overline{w^{\prime} \frac{\partial T_{E}^{\prime}}{\partial z}} .
\end{aligned}
$$

Equations (A2) and (A3) indicate the slowly varying mean SST tendency and the anomalous SST tendency (i.e., ENSO) equations, respectively, and they are linked through the nonlinear advection term. Thus, the nonzero $-\overline{w^{\prime} \partial T_{E}^{\prime} / \partial z}$, which is driven by the nonlinear process of ENSO, will be rectified into the mean (i.e., $\overline{T_{E}}$ ).

Now, we convert the NDH term $-w^{\prime} \partial T_{E}^{\prime} / \partial z$ to a finitedifference form to understand its role:

$$
-w^{\prime} \frac{\partial T_{E}^{\prime}}{\partial z} \approx-w^{\prime} \frac{\left(T_{E}^{\prime}-T_{\mathrm{sub}}^{\prime}\right)}{H_{S}}
$$

where the upwelling velocity $w^{\prime}$ is proportional to the surface zonal wind stress anomaly (the westerly drives the downwelling anomaly) and the surface zonal wind stress along the equator is also approximately proportional to the zonal gradient of the SST anomaly (Lindzen and Nigam 1987) such that $w^{\prime} \propto-\tau_{X}^{\prime} \propto-T_{E}^{\prime}$. Here $T_{\text {sub }}^{\prime}$ is a subsurface temperature where the water is entrained into the ocean surface layer, and it can be parameterized by the oceanic vertical stratification and thermocline depth anomaly; that is, $T_{\text {sub }}^{\prime} \approx \gamma h_{E}^{\prime}$ [see appendix B of An et al. (2008) and Jin (1997)]. Thus, after applying the above rules, Eq. (A4) becomes

$$
-w^{\prime} \frac{\left(T_{E}^{\prime}-T_{\mathrm{sub}}^{\prime}\right)}{H_{S}} \approx \frac{1}{H_{S}}\left(T_{E}^{\prime 2}-\gamma T_{E}^{\prime} h_{E}^{\prime}\right) .
$$

Theoretically (Wang and Fang 1996, hereafter WF96), as well as in the observation (Zelle et al. 2004), $h_{E}^{\prime}$ slightly leads $T_{E}^{\prime}$ in time, and their correlation is positive. Equation (A5) is almost identical to Eq. (3.5a) of WF96. According to WF96, the reasonable value of $\gamma$ is slightly greater than one, when the above system is normalized. Note that Dewitte and Périgaud (1996) also showed that $\gamma$ can depend on the sign of $h_{E}^{\prime}, \gamma$ being larger for positive $h_{E}^{\prime}$ than for negative $h_{E}^{\prime}$ in the eastern equatorial Pacific. Therefore, (A5) usually has a negative value indicating that the nonlinear dynamical advection term promotes the negative SST anomaly tendency. Thus, the cooling due to this second-order-that is, nonlinearterm results in a negative skewness of $T_{E}^{\prime}$ (i.e., weaker El Niño and stronger La Niña), which will be rectified into the climate state. The negative skewness is a solution obtained from a prototype ENSO model of WF96 (see their Figs. 5 and 7), while the observed ENSO usually has a positive skewness (An and Jin 2004). This contradiction may be due to immoderate simplification or possibly inadequate parameterization of a prototype ENSO model in treating the ocean wave dynamics. A clearer explanation will be addressed in a future study.

\section{REFERENCES}

Alexander, M. A., C. Deser, and M. S. Timlin, 1999: The reemergence of SST anomalies in the North Pacific Ocean. J. Climate, 12, 2419-2431.

An, S.-I., 2009: A review on interdecadal changes in the nonlinearity of the El Niño-Southern Oscillation. Theor. Appl. Climatol., 97, 29-40.

, and F.-F. Jin, 2000: An eigen analysis of the interdecadal changes in the structure and frequency of ENSO mode. Geophys. Res. Lett., 27, 2573-2576.

— , and B. Wang, 2000: Interdecadal change of the structure of the ENSO mode and its impact on the ENSO frequency. J. Climate, 13, 2044-2055.

_ and F.-F. Jin, 2004: Nonlinearity and asymmetry of ENSO. J. Climate, 17, 2399-2412.

- A. Timmermann, L. Bejarano, F.-F. Jin, F. Justino, Z. Liu, and A. W. Tudhope, 2004: Modeling evidence for enhanced El Niño-Southern Oscillation amplitude during the Last Glacial Maximum. Paleoceanography, 19, PA4009, doi:10.1029/ 2004PA001020.

, Y.-G. Ham, J.-S. Kug, F.-F. Jin, and I.-S. Kang, 2005a: El Niño-La Niña asymmetry in the Coupled Model Intercomparison Project simulations. J. Climate, 18, 2617-2627.

, W. W. Hsieh, and F.-F. Jin, 2005b: A nonlinear analysis of the ENSO cycle and its interdecadal change. J. Climate, 18, 3229-3239.

-, J.-S. Kug, A. Timmermann, I.-S. Kang, and O. Timm, 2007: The influence of ENSO on the generation of decadal variability in the North Pacific. J. Climate, 20, 667-680.

,-- , Y.-G. Ham, and I.-S. Kang, 2008: Successive modulation of ENSO to the future greenhouse warming. J. Climate, 21, 3-21. 
Bejarano, L., 2006: Coexistence of leading equatorial coupled modes for ENSO. Ph.D. dissertation, The Florida State University, $118 \mathrm{pp}$.

Burgman, R. J., P. S. Schopf, and B. P. Kirtman, 2008: Decadal modulation of ENSO in a hybrid coupled model. J. Climate, 21, 5482-5500.

Cane, M. A., and M. Evans, 2000: Climate variability-Do the tropics rule? Science, 290, 1107-1108.

Chang, P., L. Ji, H. Li, and M. Flügel, 1996: Chaotic dynamics versus stochastic processes in El Niño-Southern Oscillation in coupled ocean-atmosphere models. Physica D, 98, 301-320.

Cibot, C., 2004: Variabilité décennale dans le Pacifique tropical et modulation basse fréquence de l'activité ENSO. Ph.D. thesis, Université Paul Sabatier, Toulouse, France, 164 pp.

— E. Maisonnave, L. Terray, and B. Dewitte, 2005: Mechanisms of tropical Pacific interannual-to-decadal variability in the ARPEGE/ORCA global coupled model. Climate Dyn., 24, 823-842.

Déqué, M., C. Dreveton, A. Braun, and D. Cariolle, 1994: The ARPEGE/IFS atmosphere model: A contribution to the French community climate modeling. Climate Dyn., 10, 249-266.

Dewitte, B., and C. Périgaud, 1996: El Niño-La Niña events simulated with Cane and Zebiak's model and observed with satellite or in situ data. Part II: Model forced with observations. J. Climate, 9, 1188-1207.

, C. Cibot, C. Périgaud, S.-I. An, and L. Terray, 2007a: Interaction between near-annual and ENSO modes in a CGCM simulation: Role of equatorial background mean state. J. Climate, 20, 1035-1052.

— , S.-W. Yeh, B.-K. Moon, C. Cibot, and L. Terray, 2007b: Rectification of the ENSO variability by interdecadal changes in the equatorial background mean state in a CGCM simulation. J. Climate, 20, 2002-2021.

Fedorov, A. V., and S. G. Philander, 2000: Is El Niño changing? Science, 288, 1997-2002.

Fichefet, T., and M. A. Morales Maqueda, 1997: Sensitivity of a global sea ice model to the treatment of ice thermodynamics and dynamics. J. Geophys. Res., 102, 12 609-12 646.

Gu, D., and S. G. H. Philander, 1997: Interdecadal climate fluctuations that depend on exchanges between the tropics and extratropics. Science, 275, 805-807.

Guilyardi, E., 2006: El Niño-mean state-seasonal cycle interactions in a multi-model ensemble. Climate Dyn., 26, 329-348.

Holland, C. L., R. B. Scott, S.-I. An, and F. W. Taylor, 2007: Propagating decadal sea surface temperature signal identified in modern proxy records of the tropical Pacific. Climate Dyn., 28, 163-179.

Hsieh, W. W., 2001: Nonlinear principal component analysis by neural networks. Tellus, 53A, 599-615.

,2004: Nonlinear multivariate and time series analysis by neural network methods. Rev. Geophys., 42, RG1003, doi:10.1029/ 2002RG000112.

_ 2007: Nonlinear principal component analysis of noisy data. Neural Networks, 20, 434-443.

Jin, F.-F., 1997: An equatorial ocean recharge paradigm for ENSO. Part I: Conceptual model. J. Atmos. Sci., 54, 811-829.

- 2001: Low-frequency modes of tropical ocean dynamics. J. Climate, 14, 3874-3881.

_- M. Kimoto, and X. Wang, 2001: A model of decadal oceanatmosphere interaction in the North Pacific basin. Geophys. Res. Lett., 28, 1531-1534.
_ _ S.-I. An, A. Timmermann, and J. Zhao, 2003: Strong El Niño events and nonlinear dynamical heating. Geophys. Res. Lett., 30, 1120.

Kessler, W. S., and R. Kleeman, 2000: Rectification of the MaddenJulian oscillation into the ENSO cycle. J. Climate, 13, 35603575 .

Kirtman, B. P., and P. S. Schopf, 1998: Decadal variability in ENSO predictability and prediction. J. Climate, 11, 2804 2822.

Kleeman, R., J. P. McCreary, and B. A. Klinger, 1999: A mechanism for generating ENSO decadal variability. Geophys. Res. Lett., 26, 1743-1746.

Knutson, T. R., and S. Manabe, 1998: Model assessment of decadal variability and trends in the tropical Pacific Ocean. J. Climate, 11, 2273-2296.

Latif, M., and T. P. Barnett, 1994: Causes of decadal climate variability over the North Pacific and North America sector. Science, 266, 634-637.

Levitus, S., and Coauthors, 1998: Introduction. Vol. 1, World Ocean Database 1998, NOAA Atlas NESDIS 18, 346 pp.

Lindzen, R. S., and S. Nigam, 1987: On the role of sea surface temperature gradients in forcing low-level winds and convergence in the tropics. J. Atmos. Sci., 44, 2418-2436.

Madec, G., P. Delecluse, M. Imbard, and C. Lévy, 1998: OPA 8.1 ocean general circulation model reference manual. Note du Póle de modélisation 11, Institut Pierre-Simon Laplace, 91 pp.

Meehl, G. A., P. R. Gent, J. M. Arblaster, B. L. Otto-Bliesner, E. C. Brady, and A. Craig, 2001: Factors that affect amplitude of El Niño in global coupled climate models. Climate Dyn., 17, $515-526$.

Newman, M., G. P. Compo, and M. A. Alexander, 2003: ENSOforced variability of the Pacific decadal oscillation. J. Climate, 16, 3853-3857.

Nonaka, M., S.-P. Xie, and J. P. McCreary, 2002: Decadal variations in the subtropical cells and equatorial pacific SST. Geophys. Res. Lett., 29, 1116, doi:10.1029/2001GL013717.

Penland, C., and P. D. Sardeshmukh, 1995: The optimal growth of tropical sea surface temperature anomalies. J. Climate, $\mathbf{8}$, 1999-2024.

Rodgers, K. B., P. Friederichs, and M. Latif, 2004: Tropical Pacific decadal variability and its relation to decadal modulations of ENSO. J. Climate, 17, 3761-3774.

Saravanan, R., and J. C. McWilliams, 1997: Stochasticity and spatial resonance in interdecadal climate fluctuations. J. Climate, 10, 2299-2320.

Schopf, P. S., and R. J. Burgman, 2006: A simple mechanism for ENSO residuals and asymmetry. J. Climate, 19, 3167-3179.

Sun, D.-Z., and T. Zhang, 2006: A regulatory effect of ENSO on the time-mean thermal stratification of the equatorial upper ocean. Geophys. Res. Lett., 33, L07710, doi:10.1029/2005GL025296.

Sun, F., and J.-Y. Yu, 2009: A 10-15-year modulation cycle of ENSO intensity. J. Climate, 22, 1718-1735.

Thompson, C. J., and D. S. Battisti, 2000: A linear stochastic dynamical model of ENSO. Part I: Model development. J. Climate, 13, 2818-2832.

Timmermann, A., 2003: Decadal ENSO amplitude modulations: A nonlinear paradigm. Global Planet. Change, 37, 135-156. , and F.-F. Jin, 2002: A nonlinear mechanism for decadal El Niño amplitude changes. Geophys. Res. Lett., 29, 1003, doi:10.1029/2001GL013369.

_, M. Latif, A. Bacher, J. Oberhuber, and E. Roeckner, 1999 Increased $\mathrm{El}$ Niño frequency in a climate model forced by future greenhouse warming. Nature, 398, 694-697. 
, F.-F. Jin, and J. Abshagen, 2003: A nonlinear theory for El Niño bursting. J. Atmos. Sci., 60, 152-165.

Torrence, T., and P. J. Webster, 1998: Interdecadal changes in the ENSO-monsoon system. J. Climate, 12, 2679-2690.

Valcke, S., L. Terray, and A. Piacentini, 2000: The OASIS coupled user guide version 2.4. Tech. Rep. TR/CMGC/00-10, CERFACS, $85 \mathrm{pp}$.

Vimont, D. J., D. S. Battisti, and A. C. Hirst, 2003: The seasonal footprinting mechanism in the CSIRO general circulation models. J. Climate, 16, 2653-2667.

Wang, B., and Z. Fang, 1996: Chaotic oscillations of tropical climate: A dynamic system theory for ENSO. J. Atmos. Sci., 53, 2787-2802.

—, and S.-I. An, 2001: Why the properties of El Niño changed during the late 1970s. Geophys. Res. Lett., 28, 3709-3712.

Wang, X. L., and C. F. Ropelewski, 1995: An assessment of ENSOscale secular variability. J. Climate, 8, 1584-1599.
Ye, Z., and W. W. Hsieh, 2006: The influence of climate regime shift on ENSO. Climate Dyn., 26, 823-833.

Yeh, S.-W., and B. Kirtman, 2004: Tropical Pacific decadal variability and ENSO amplitude modulation in a CGCM. J. Geophys. Res., 109, C11009, doi:10.1029/2004JC002442.

_, and —_, 2009: Internal atmospheric variability and interannualto-decadal ENSO variability in a CGCM. J. Climate, 22, 2335-2355.

Zebiak, S. E., and M. A. Cane, 1987: A model El Niño-Southern oscillation. Mon. Wea. Rev., 115, 2262-2278.

Zelle, H., G. Appeldoorn, G. Burgers, and G. J. V. Oldenborgh, 2004: The relationship between sea surface temperature and thermocline depth in the eastern equatorial Pacific. J. Phys. Oceanogr., 34, 643-655.

Zhang, Y., J. M. Wallace, and D. S. Battisti, 1997: ENSO-like interdecadal variability: 1900-93. J. Climate, 10, 1004-1020. 